\title{
The Effect of Modern Lyrical Music on Second Language Vocabulary Acquisition
}

\author{
Atefeh Yousefi \\ Department of Linguistics and foreign languages, Payam Noor University \\ yousefi.nika@yahoo.com \\ Razieh Rabbani Yekta \\ Department of Linguistics and foreign languages, Payam Noor University \\ r_ryekta@yahoo.com \\ Hamid Farahmandian* \\ Faculty of Modern Languages and Communication, Universiti Putra Malaysia \\ FarahmandianH@gmail.com
}

\section{Doi:10.5901/mjss.2014.v5n23p2583}

\section{Abstract}

In recent studies, vocabulary acquisition has received a high premium as it plays an important role in second language acquisition .Yet in the midst of increasing satisfaction with the field's maturity, a number of rather fundamental questions remained unanswered. One of the most important questions concerned the effect of music on second language vocabulary acquisition .The aim of this study is to a) investigate the effect of music on second language vocabulary acquisition; b) investigate the effect of music on long term retention of vocabulary. For this purpose sixty girl students of a junior high school were randomly selected and assigned to two groups of thirty. The first group (experimental group) was the music group, the second (control group was the no music group. The effect of treatment on vocabulary acquisition was assessed immediately after the treatment. The research hypotheses was :1)music has no effect on vocabulary acquisition of students in junior high school in Iran 2) music has no effect on long term retention of vocabulary. The analysis of the collected data through applying $t$ test revealed that there was a significant differences between the two groups. The music group outperformed the no-music group both in short and long term retention. The results show that music has positive effect on vocabulary acquisition .Therefore the null hypotheses was rejected.

Keywords: acquisition, music, vocabulary, t-test, second language

\section{Introduction}

Language learning is the most complex type of learning among human being .Within language learning vocabulary plays an important part in second language. in spites of its critical importance; however, the field of vocabulary acquisition was a neglected area until quite recently .After a long time of being concentrated with the development of grammatical competence, language teachers and SLA researchers now recognized the place of vocabulary .Weatherford (1990) states that since a 5000 words basic vocabulary is required for making meaning in a foreign language, acquiring these words by any means possible must be one of the priorities.

According to Shunk (1999) one way to increase learners vocabulary knowledge is using music .It is currently a common practice to use songs in the classroom to support second language acquisition (Jalongo and Bromley1984; Martin ,1983;Mitchel,1983;Jolly,1975).Whitaker(1981) asserts that music aids in all four major language areas -in listening ,speaking reading and writing .Mora asserts that verbal practice associated with musical information seems to be memorable .Using melody with new phrases, lowers the student's anxiety and foreign sounds paired with music will be stored in long term musical memory and accessible for mental rehearsal and memorization (Mora,2000) .Repetition is one of the ways the brain remembers material, and is known in some cultures as the mother of learning . 


\section{Literature Review}

\subsection{Music and Language}

Joanne Lowey (1995) proposes that language should be considered not in a cognitive context but in a musical one .Pre linguistically, music is the carrier of communicative intent. Infant produce intonation within crying and babbling . This intonation has communicative purpose. These are the infants first audible expression of emotional need( Loewy,1995).Because there are no words involved, all of this communication comes through the musical elements of the cry. Through words and sentences are a few steps away.

\subsection{Music and the Brain}

According to Weinberger (1994) learning and performing music actually exercise the brain by strengthening the synapses between brain cells. He asserts synapses grow stronger through use and become weakened through disuse The connection between neurons increases the brains's capacity.

Elliot (1995) asserts in order to process music, the brain set up neural high way or synapses to receive and analyze data. This electrical high and chemical pathway then can be used for processing other information such as language and mathematics.

\subsection{Music and Verbal Memory}

According to a new study children with music training had significantly better verbal memory than their counterpart without such training (Chan, $\mathrm{Ho}_{0}$, and Cheung, 2003). They propose that music training during childhood is a kind of sensory stimulation that contributes to the reorganization and better development of the left temporal lobe in musicians, which facilitates cognitive processing mediated by that specific brain area, That is verbal memory.

\section{Methodology}

The purpose of the present study is to investigate whether music helps students develop L2 lexical storage. In order to achieve this goal, sixty girl students were selected randomly from ninety students in junior high schools. Then they were randomly assigned to two equal groups and the decision as to which group will be the experimental group was also decided randomly. The design of the study was pretest posttest control group design.

\section{Materials}

The materials which were included in this study contained 15 recorded songs with the spoken versions. These songs were chosen from chatterbox and super songs they were judge by the classroom teachers to be a little above the students present reading level.

These texts were selected because they had a number of criteria. At most basic level, these texts had the following characteristics: a) they were tape recorded songs and the spoken versions of them were recorded by a native like speakers; b) they were appropriate for the level of students; c) they also contained 100 vocabulary words which were unfamiliar to the third grade students; d) the voice heard on the tapes were clear, comprehensible, and equally appealing.

As a pilot study, before the treatment the researcher gave students 100 words from the texts to the students to write their Persian equivalents. None of these words were familiar to students.

\section{Teacher Made Test}

A teacher made test was designed to measure the students familiarity with the words and possible vocabulary gains from the test . The chief rational behind the test was to see if the participants knew the meaning of the words, teaching these new words would seem unrealistic. The test involved one hundred words selected from the pilot study mentioned above.

As the test was teacher made test the reliability ratio of the test had been calculated.The reliability of the tests was calculated using spearman -brown prophecy formula. (Spearman, 1910).

The reliability of the first posttest was equal to 0.86 and the second posttest ease quall to 0.88 .these coefficient showed that the reliability of the tests were acceptable. The content validity of the tests was also verified through logic 
and teachers opinions.

\section{Procedure}

To investigate the underlying questions of the thesis hypotheses, two control and experimental groups were selected .In this research design, the independent variable was the method of the presentation of the vocabulary items, and the dependent factor was the participants vocabulary acquisition. The participants attended English classes for 90 minutes lesson periods, 2 days a week and 8 sessions each month. The entire period experiment was two 2 months and 11 days.

First of all, the pretest was given to the students who were studying at the elementary level in both classes to make sure that none of the students knew the words. The music group heard the music versions while the no-music group heard the spoken versions.

At the end, 2 post-tests of vocabulary were administered to investigate the learners' vocabulary knowledge in both groups . The exact Persian equivalent scored one and the incorrect equivalent scored zero.

\section{Data Analysis}

In order to determine the short-term and long-term effects of music the dependent variable, vocabulary was measured before the treatment. After the treatment which took 2 months, the first posttest was conducted and in order to estimate the long term retention of vocabulary the second posttest was administered two weeks after the first posttest .t-test analysis was conducted to see whether the difference between these two groups is significant or not. The descriptive statistics for the two groups were calculated.

Table 1. The results of the t-test on the means of two groups (post-test 1 )

\begin{tabular}{|l|c|c|c|c|c|c|c|}
\hline Group & No & Mean & SD & SE Mean & df & tobs & P \\
\cline { 1 - 6 } Music group & 30 & 87.06 & 16.36 & 2.98 & \multirow{2}{*}{58} & \multirow{2}{*}{2.68} & \multirow{2}{*}{0.01} \\
\hline No-music group & 30 & 71.66 & 26.85 & 4.90 & & & \\
\hline
\end{tabular}

The main group effect was significant (t observed $=2.68$ ) which suggest participants in the music group generally recalled more words than did those in no-music group. As it was shown the music group outperformed the no music group .It follows then that music has positive effect on second language vocabulary acquisition.

In order to determine the long-term retention of vocabulary, the second post-test was administered two weeks after the first posttest.

\begin{tabular}{|l|c|c|c|c|c|c|c|}
\hline Group & No & Mean & SD & SE Mean & df & T obs & $p$ \\
\hline Music group & 30 & 76.2 & 21.42 & 3.91 & \multirow{2}{*}{58} & \multirow{2}{*}{4.3} & \multirow{2}{*}{0.01} \\
\hline Nomusic group & 30 & 50.46 & 24.77 & 4.52 & & & \\
\hline
\end{tabular}

The results indicate that participants in the music group generally had better verbal retention ability than those in the nomusic group on long term retention of vocabulary. The second null hypotheses was also rejected .

\section{Discussions}

Mean scores of the music -group immediately after the treatment in post-test (1) was 87.066 and the mean gain scores of the no-music group was 2.86. The results indicated that the high significant main effect for this factor that is ,music ,so the first null hypotheses was rejected.

\section{Research Hypotheses 2}

2. The second question was intended to investigate the performance of participants two weeks later after the treatment in order to investigate the long term retention of vocabulary.

The mean gain scores of the music group was 76.2 and the mean score of the no-music group was 50.46 . The observed was equal to 4.3.The result indicate that music has positive effect on long term retention of vocabulary. The second null hypothesis was also rejected. 


\section{Conclusions}

As it was shown, the music group outperforms the no-music group .It follows then that music has positive effect on second language vocabulary both in short and long term retention. The finding is consistent with the statement which have been made regarding the efficiency of music on first and second language acquisition (Mc Carthy, 1985)

According to Krashen's input hypotheses vocabulary is acquired when its meaning is made clear to the learner .Meaning is conveyed by providing extra linguistics supports such as actions ,photos, and realia .This ,in turn ,results in refers to a "comprehensible input " since the linguistic input is made comprehensible to the second language learners. Thus, vocabulary is incidentally acquired through stories because familiar vocabulary and syntax contained in the stories provide meaning to less familiar vocabulary. Songs have all of the same basics of oral stories excluding song, is musical rather than spoken

The results of this study are also consistent with the effect of music on other types of verbal information .Evidence shows that music benefits rote memorization when various types of verbal information (e.g, multiplication tables, spelling lists) have been presented with music, memorization has been enhanced (Gfeller, 1983).According to Asher (1973) a rhythmic presentation benefits memorization, especially when the verbal information is meaningful.

Beaton (1995) describes the benefits of using music in language classroom .Stansell (2005) claims that music positively affects on mind, language, healing as well as mood, motivation and enjoyment.

It is also consistent with the statement that music has the ability to facilitate language acquisition, reading readiness and general intellectual development to provide positive attitude and to lower anxiety in middle and high school; to enhance creating; and promote social development personality adjustment and self -worth (Hanshumaker,1980). According to Wittaker (1981) whereas music can benefit grammar, pronunciation cultural appreciation, vocabulary is considered as one of the most important part of language that music can benefit it.

\section{Implication}

The finding of this study shed light on the basic idea of Krashen's hypotheses. According to affective filter hypotheses learning occur in an environment of high motivation self -confidence and low anxiety (Ellis, 1986). According to this hypotheses the emotional states of the learner acts as a filter. Krashen asserts that learner's emotional state of the learner acts as a filter. That may pass or impede input needed for acquisition.

Gardener theory of Multiple Intelligence also supports the use of music .He mentions that music and linguistic intelligences are related to each other and the outcome is greater because of the cooperation. Lezar (1991) states that learning is most successful when we consider the combination of intelligences

Absolutely ,music offers great opportunities for communication ,for creativity and group cooperation .It's good for the brain and enhance learning and intellectual development .Instead of asking "why music" e might ask" why not music "?and "how can I use music to my students to develop my goals as an educator ?"

\section{References}

Anton,R.J.(1990).combining singing and psychology.Hipania,73,1160-1170

Asher,J.(1990)Combining Singing and psychology.Hispania,73,1160-1170

Beaton,P.(1995). The importance of music in the early childhood language curriculum.International school Journal.15(1),28-38.

Brown,H.D.(1994).Principles of Language Learning and Teaching .Englewood Cliffs,NJ:Prentice-Hall

Cain,R.N., and Cain ,G.(1994).Making connections.Menlo Park:Addison Wesley..

Ellis,R.(1997).Vocabulary acquisition :Oxford:Oxford University Press.

Gfller,K.E.(1986).Musical mnemonics as an aid to retention with normal

Hanshumaker, J(1980). The effect of arts education on intellectual and social development :Areview of selected research .Bulletin of the Council for Research in Music Education,61,10-28.

Krashen,S. (1992).principles and Practice in Second Language Acquisition .New York:Longman

Lezar,D.(1991).Seven Ways of Knowing :Teaching for multiple intelligences, $\left(2^{\text {nd }} \mathrm{ed}\right)$. Palatine:IRI

Mac carthy ,M.J.(1984).A new look at vocabulary in EFL -Applied Linguistics ,5,12-22 Publishing

Medina ,S(2004).The effect of music on second language Vocabulary.Retrieved July 2004,fromhttp://www.forefront

Meara,P.(1980)Vocabulary Acquisition .Pictures and Second language comprehension.Do

Riper ,C.(1984) Speech Correction :An introduction to speech pathology and audiology. Englewood Cliffs,NJ:Prentice Hall.

Rausher ,F.H(1995)Listening to Mozart enhances spatial-temporal reasoning .Nature,17(2),45-63.

Stansell,J.W.(2005). The use of music in learning language :A Review[on line].University of Illinoise at Urbana -Champain .

Whittaker,F.(1981).Singing in ESL with songs for the grammar class. Honlolulu ,HI(ERIC Document Reproduction Service No.ED207336) 